\title{
MUITO ALÉM DE UM PATINHO TORTO: \\ A utilização estratégica da Cultura Popular para um alcance maior de público
}

\author{
Luiz Campos ${ }^{1}$
}

\begin{abstract}
RESUMO
O Grupo Decisão da cidade de São Paulo, traz montagens inovadoras do ponto de vista do Teatro Épico e do Teatro Brechtiano vindas da Europa. Bagagem esta trazida por Antonio Abujamra, um de seus diretores e fundadores. Depois de uma sequência de Lope de Vega, dois textos de Bertolt Brecht e de Harold Pinter, o Grupo opta pelo primeiro texto brasileiro, o autor escolhido é Coelho Neto, e a peça uma comédia de costumes chamada de "O patinho torto" ou "Os mistérios do sexo" dirigida por Antonio Ghigonetto. $\mathrm{O}$ presente artigo visa expor os indícios documentais, recuperados da montagem, que nos faça ter hipóteses dos motivos do Grupo Decisão a escolha deste texto.
\end{abstract}

PALAVRAS-CHAVE: Grupo Decisão, Antonio Ghigonetto, Coelho Neto, teatro brasileiro, cultura popular.

\section{RESUMEN}

El Grupo Decisión de la ciudad de São Paulo, trae montajes innovadores desde el punto de vista del Teatro Épico y del Teatro Brechtiano venidos de Europa. El equipaje esta traído por Antonio Abujamra, uno de sus directores y fundadores. Después de una secuencia de Lope de Vega, dos textos de Bertolt Brecht y de Harold Pinter, el Grupo opta por el primer texto brasileño, el autor elegido es Coelho Neto, y la pieza una comedia de costumbres llamada "El patito torcido" o " Los misterios del sexo "dirigida por Antonio Ghigonetto. El presente artículo pretende exponer los indicios documentales, recuperados del montaje, que nos haga tener hipótesis de los motivos del Grupo Decisión la elección de este texto.

PALABRAS CLAVE: Grupo Decisión, Antonio Ghigonetto, Coelho Neto, teatro brasileño, cultura popular.

\begin{abstract}
The Decision Group of the city of São Paulo, bringing the innovators from the point of view of the Epic Theater and the Brechtian Theater coming from Europe. Luggage is brought by Antonio Abujamra, one of its directors and financiers. After a Lupa de Vega, two texts by Bertolt Brecht and Harold Pinter, Group The first Brazilian text, the author is called Coelho Neto, and a costumes comedy called "The crooked duckling" or "The mysteries of sex" directed by Antonio Ghigonetto. The main article is to present document documents, recovered from the assembly, which seems to us to be hypothesis of the reasons of the Group Decision instead of this text.

KEYWORDS: Decision Group, Antonio Ghigonetto, Coelho Neto, teatro brasileiro, popular culture.
\end{abstract}

\footnotetext{
${ }^{1}$ Luiz Campos é ator, diretor e pesquisador teatral. É ator convidado da Cia. Ocamorana e diretor da Cia. Los Puercos, ambas da cidade de São Paulo. Possui licenciatura em Teatro pela Faculdade Paulista de Artes e atualmente é Mestrando em Teatro pela UFSJ (Universidade Federal de São João Del-Rei). Recentemente publicou o livro "Ghigonetto, um homem de teatro".
} 


\section{INTRODUÇÃO}

No ano de 1963, na cidade de São Paulo, é fundado por Antonio Abujamra, Antonio Ghigonetto, Emílio Di Biasi, Berta Zemel, Wolney de Assis, Lauro César Muniz e Sérgio Mamberti, o Grupo Decisão. Este artigo foi consequência dos resultados de pesquisa de mestrado, realizado por este autor no grupo de pesquisa "História, política e cena" da Universidade Federal de São João Del-Rei (UFSJ), visando realizar o levantamento documental (programas, críticas e entrevistas) do referido grupo.

"O patinho torto" ou "Os mistérios do sexo"é um texto de Coelho Neto, dramaturgo brasileiro e maranhense que escreveu mais de 50 peças para o teatro. No ano de 1964, ano do seu centenário (1864 -1932), o Grupo Decisão decide, aparentemente para homenageá-lo, montar a comédia do autor que na época, segundo algumas críticas e entrevistas, obteve certa popularidade por parte do seu público. Naquele período o Grupo já continha em seu repertório peças ousadas como: "Sorocaba, Senhor!", uma adaptação do texto de "Fuenteovejuna" de Lope de Vega; "Terror e miséria do III Reich"; "Os fuzis da Sra. Carrar" ambas de Bertolt Brecht; e por último "O Inoportuno" de Harold Pinter. O grupo, decide montar naquele ano, a comédia brasileira "O patinho torto", fugindo dos moldes de seu repertório, até então com textos de cunho social e político nos gêneros dramáticos e com inserções épicas. Outro detalhe é que pelo que apontam os registros documentais levantados nesta pesquisa, a peça de Coelho Neto teve sua primeira montagem somente pelo Grupo Decisão.

Apresentarei a seguir, um pouco sobre essa obra dramatúrgica e também a montagem de 1964, realizada pelo Grupo Decisão, relacionando com indícios do entendimento de "Cultura Popular" sobre o ponto de vista de Stuart Hall e Martha Abreu. Através dos documentos colhidos que teve início em minha pesquisa de iniciação cientifica e que certamente vem colaborando com os documentos colhidos para a referida dissertação de mestrado. Os documentos explicitados para relação de cultura popular, acerca do Grupo 
Decisão, são parte dos resultados desta intensa pesquisa, são eles: uma crítica de Almir Azevedo e depoimentos exclusivos de Amir Haddad e João das Neves, além das imagens da montagem.

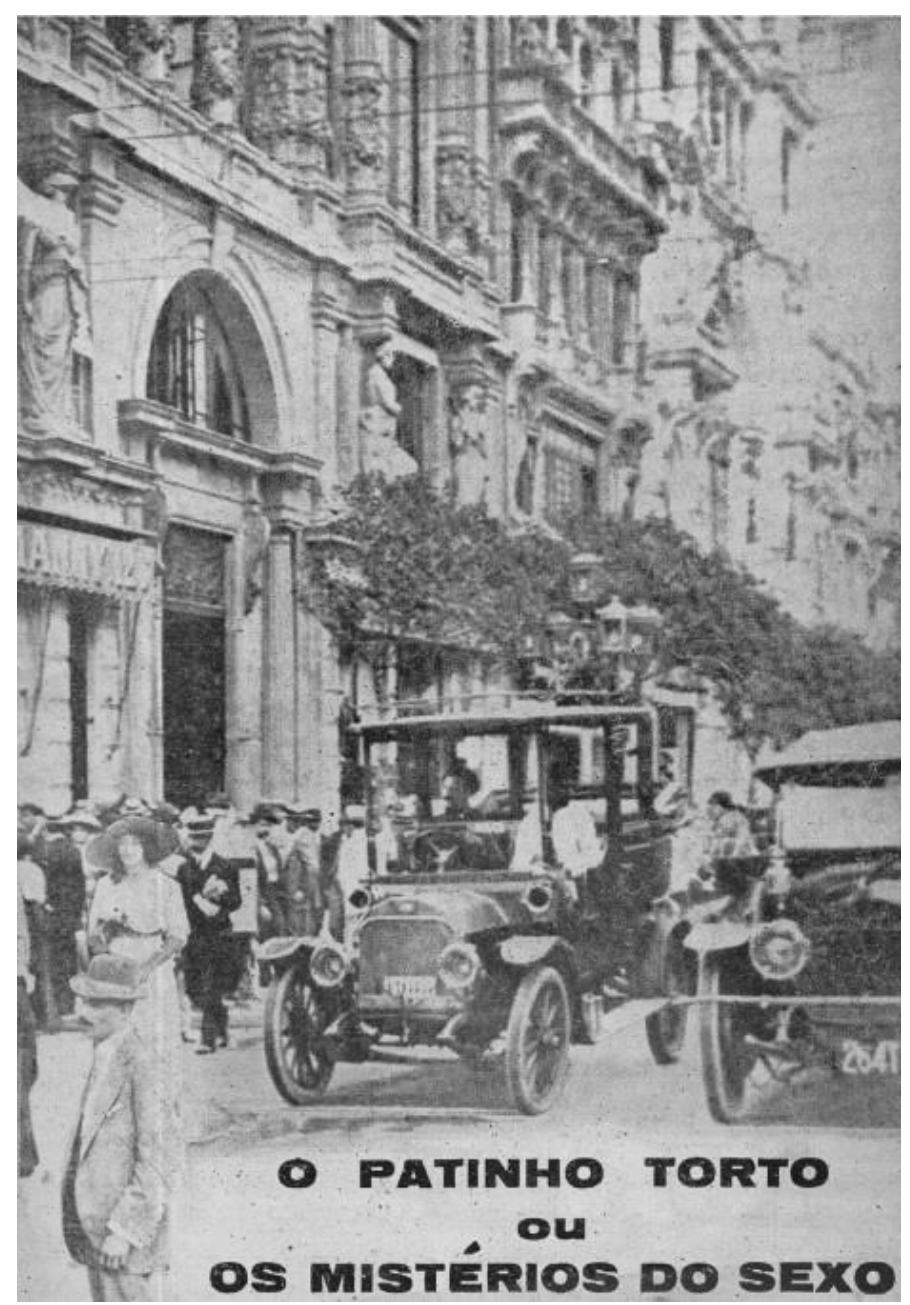

Foto 1. Capa do programa "O patinho torto" de Coelho Neto. Direção: Antonio Ghigonetto pelo Grupo Decisão. Acervo: Luiz Campos

\section{O TEXTO}

O texto é inspirado num fato verídico. Uma notícia de jornal, na qual ainda não se teve acesso, do dia 16 de outubro de 1917, na primeira página da Gazeta de Notícias, do Rio de Janeiro, de uma prescrição médica atestando que: "Emília Soares é homem". A peça, dividida em três atos, chama atenção pela temática apresentada na época. 
Na peça, Eufêmia é uma jovem de 18 anos, que está prestes a casar com Bibi, filho de seu padrinho Clemente. Porém, ela oferece uma certa resistência ao casamento, que é imposto pelos pais, demostrando assim uma forte personalidade. Oriunda de uma família tradicional, Eufêmia chama atenção ao que diz respeito aos padrões comportamentais de uma moça, pois "ela" além de responder de forma agressiva o seu noivo, joga futebol e tem o sonho de servir a guerra. Coisas que para época eram tabus da sociedade.

Contrariando a família, "ela" demonstra também, ao decorrer do texto, relações conflituosas com as demais personagens da trama. Após algumas atitudes e desafiando os costumes tradicionais corriqueiros do período, Eufêmia visita o médico, Doutor Patureba, e passa a trajar-se e comportar-se definitivamente como homem, causando perplexidade em sua família, que não aceita seu novo estado. Já seu noivo, mesmo triste e assustado, de certa forma aceita a ideia de que sua noiva seja agora um homem.

O texto mesmo sendo muito sútil quando comparado nos nossos tempos atuais, expressa a liberdade sexual entre homens e mulheres, e de certa forma a luta feminista no que diz respeito a independência equidade da mulher, pois suas atitudes e opiniões contrastam com os moldes da figura feminina naquele período histórico no Brasil.

\section{EM BUSCA DE UMA MONTAGEM "POPULAR"}

Se hoje, o tema sobre diversidade sexual já gera alguns conflitos, imaginem a recepção deste texto e do espetáculo, no início do século XX. Portanto, não podemos ignorar as influências deste período, tanto para o autor, para deixar o texto de certa forma leve, - e não é à toa que foi escrito como comédia - e também ao diretor, para atrair o interesse do público, numa comédia que aborda temas delicados. 
O espetáculo estreou no dia 14 de julho de 1964, na cidade do Rio de Janeiro, no antigo TNC (Teatro Nacional de Comédia), com dois nomes "Patinho torto" ou “Os mistérios do sexo", segundo relatos, para não aparentar nas divulgações da época, ser uma peça infantil. E depois de algumas críticas favoráveis, o espetáculo vai para cidade de São Paulo, onde encerra sua temporada no ano de 1965. Nessa pesquisa, o "Patinho torto" é o espetáculo mais rico, com relação quantitativa dos materiais encontrados, nos jornais da época e textos dos críticos. Com relação as críticas que se teve acesso da época, os elogios não faltaram para a montagem, que contava como a direção de Antonio Ghigonetto, e um elenco na maior parte composto por jovens, mas que na atualidade a maioria agigantam suas trajetórias, são eles: Sérgio Mamberti, Carlos Vereza, Suely Franco, Emílio di Biasi, Hulda Machado, Marilena Carvalho e a única veterana daquele período Iracema de Alencar.

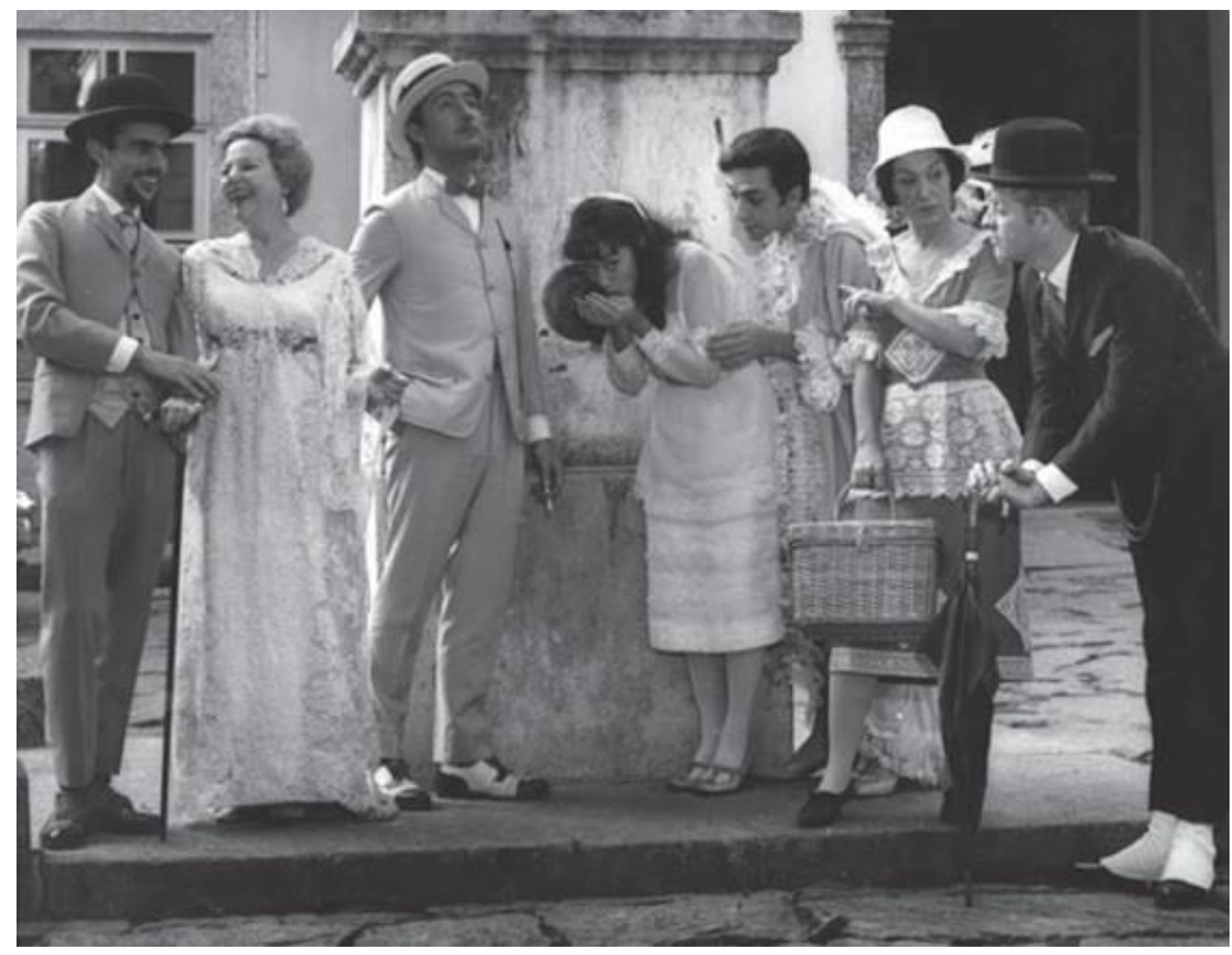

Foto 2. Elenco do O patinho torto. Na foto da esquerda para direita: João das Neves, Iracema de Alencar, Sérgio Mamberti, Suely Franco, Emilio Di Biasi, Hilda Machado e Carlos Vereza. Acervo: Luiz Campos. 
A seguir, um pequeno trecho da crítica de Almir Azevedo, para podermos ter uma dimensão do que foi o "Patinho torto" aos olhos da imprensa daquele ano.

"O Patinho Torto" (título ingênuo e inexpressivo, que mais lembra teatro infantil) ou "Os Mistérios do Sexo" (bem mais sugestivo), para despertar interesse, dependerá sempre e muito da direção e da interpretação do elenco. Isso porque, como peça, de tão frágil e primária, não resistiria a uma análise crítica mais acurada. Contudo, não se pode negar que o espetáculo ora apresentado no Teatro Nacional de Comédia recomenda-se sob vários ângulos. Pelo capricho da montagem, com bonitos e sugestivos cenário e figurinos de época, de Carlos Sórensen; pela homogeneidade do desempenho; mas, sobretudo, pelo delicioso ritmo da direção de Antonio Ghigonetto com marcações muito interessantes e felizes. A sua direção, principalmente, deve-se o agrado do espetáculo, um dos mais aplaudidos a que tenho assistido ultimamente. Em nenhum momento da representação há quebra de ritmo e o riso espouca franco e fácil, na plateia, não tanto pelo que de engraçado possa conter o texto, mas pelos recursos utilizados pela direção, muito bem ajudada pelos interpretes. (AZEVEDO, 1964, p. 4)

Percebemos na escrita de Almir Azevedo, realizada para montagem do Rio de Janeiro, uma certa surpresa, ao ver na peça, que denomina de "frágil" e "primária", tamanha satisfação com seu público. Também percebemos que o texto na sua visão é fraco, mas destaca por vezes a direção, pois para o crítico, a direção foi inventiva, utilizando recursos que colaboraram para esse estreitamento com seu público.

Quando o Grupo Decisão trouxe a peça para a cidade de São Paulo, isso já era no ano de 1965, seu elenco além de sofrer alterações, e para atrair público ao espetáculo adotaram de uma estratégia um tanto curiosa. Os atores e atrizes vestiam seus figurinos, e saíam como suas personagens pelas ruas de São Paulo anunciando a peça. O fato em si, assemelha-se a cortejos, ritos dionisíacos ou nossos carnavais brasileiros. Obviamente que isso trouxe não só uma identificação, mas um diálogo com seu público. Após o acesso de mais materiais, percebo que essa prática foi feita pelo Grupo Decisão, na sua temporada no Rio de Janeiro, e que deu muito certo. Heleniara Amorim Moura, que realizou um artigo sobre a atriz Lysia de Araújo nos anos de 1960, utiliza o termo "popularização da arte teatral" para este fato em si: 
A trupe de atores, entre eles Emílio de Biasi, Luiz Mendonza, Sérgio Mamberti, Carlos Vereza e Cecília Carneiro, divulgaram o espetáculo nas ruas de São Paulo e trabalharam de maneira árdua para a popularização da arte teatral. (MOURA, 2016, p. 17)

Entendo que a escolha da direção com o "Patinho torto" foi de trazer o texto para uma cultura mais popular. A escolha do grupo com um texto cômico, e de autor brasileiro, foram propositais para um alcance de aproximação, identificação e diálogo maior com seu público. Isso de certa maneira, nos remete também ao antigo teatro grego, pois a comédia era feita para os homens inferiores, os que naquela época eram os homens comuns, da polis. O Decisão desde sua fundação, buscava essa aproximação com o público, em uma nota de jornal, cuja fonte ainda não foi possível ser revelada, Berta Zemel, fundadora do Grupo, revela: "Queremos levar ao teatro um público que nunca foi ao teatro" e mais adiante completa: "Queremos uma representação brasileira. Não só na maneira de encarar as situações, mas de dize-las. Em nossos palcos fala-se tudo menos o português."

Nesse caso em específico, eles estavam "enfrentando" "operando" na prática uma popularização do teatro que acreditavam, termos usados por Martha Abreu (2003) a seguir, que juntamente com Stuart Hall (2003) nos ajudam para a compreensão da cultura popular:

A cultura popular não é, num sentido "puro", nem as tradições populares de resistência a esses processos, nem as formas que sobrepõem. É o terreno sobre o qual as transformações são operadas. (HALL, 2003, p.248)

Como já afirmei em outra oportunidade, cultura popular não é um conceito passível de definição simples ou a priori. Cultura popular não é um conjunto fixo de práticas, objetos ou textos, nem um conceito definido aplicável a qualquer período histórico. Cultura popular não se conceitua, enfrenta-se. (ABREU, 2003, p.13)

Ao mesmo tempo que recuperava as críticas publicadas nos jornais, entrevistei alguns ex-integrantes desta montagem. Queria saber um pouco, como foi realizado este processo além dos documentos encontrados. E do porquê que essa montagem foi a que mais obteve-se informações. Buscava detalhes que iriam além das críticas registradas. Descubro, em conversa realizada com João das Neves, no ano de 2014, que o diretor teatral carioca 
Amir Haddad, colaborou de forma significativa neste trabalho contribuindo com a direção de Ghigonetto e enriquecendo ainda mais a montagem. Até então, o nome de Amir Haddad, não aparece na ficha técnica, nem tampouco nas críticas. Abaixo o trecho exato em que fez deste pesquisador deparar com algo que por algum motivo não foi exposto na ficha técnica, além dos documentos colhidos.

O Ghigonetto era uma pessoa muito inventiva, mas também muito aberta ele dialogava com os atores, não só com os atores, ele abriu para outros diretores, como o Amir Haddad, para fazer alguns ensaios conosco, fazer outras experiências dentro do trabalho dele. Isso foi muito rico para a encenação! Então ele era uma pessoa muito aberta, por isso que eu acho que é um diretor excelente. (NEVES. João das Neves em entrevista para Luiz Campos em 2014)

Viajo a cidade do Rio de Janeiro, para então entrevistar o diretor Amir Haddad. Encontro esse que rendeu mais de 90 minutos de conversa acerca, não só da montagem do "Patinho torto", mas do Grupo Decisão e seus diretores: Antonio Abujamra e Antonio Ghigonetto. Então no trecho a seguir, o momento em que Amir Haddad detalha sua participação no espetáculo e sua função.

O Abujamra havia me dito: "Amir, vai dar uma olhada no Patinho Torto que está ruim". Eu fui no Teatro Maison de France assistir o ensaio, eu cheguei do Belém do Pará e fui assistir. E realmente... Era uma comédia de costumes, brasileira, da década de trinta, com humor engraçadinho, mas tudo feito [pelo Ghigonetto] sem nenhum humor da época e sem nenhuma visão moderna, era uma encenação quadrada. Essas comédias eram escritas para atores carimbadíssimos, quando chegavam lá, a atriz que iria fazer ela já fez aquele papel mil vezes, o galã que iria fazer também já havia feito, eles estreavam uma peça por semana, e botavam em cartaz nos teatros do Rio de Janeiro. E aquela coisa, já tinham os "fulanos", para tal papel tem que chamar a dama galã, já em outro é a dama central, galã romântico, o cômico... O teatro brasileiro tinha a sua escala de atores, assim como a Commedia Dell'Arte. Então o teatro tinha todas as suas máscaras já produzidas, então quando o Coelho Neto escrevia uma peça dessas ele já sabia que poderia ir para estes atores.

(...)No Patinho torto a Iracema de Alencar era a atriz a ser recuperada, maravilhosa que ela era. Ela tinha sido uma Tônia Carrero, ela tinha os olhos azuis, era loira e muito bonita, mas quando chegou pra gente ela já estava velha. Ela deixava de ser dama galã e foi ser dama central $\mathrm{O}$ elenco que o Ghigonetto tinha reunido, só tinha desse período a Iracema de Alencar, que sozinha não poderia fazer nada. $\mathrm{O}$ resto eram muito jovens, muito jovens de talento, um elenco de primeira, mas todos de começo de carreira. Eu imagino que o Ghigonetto não soube o que fazer com isso.

Então o Abujamra me chamou, e quando cheguei lá era muito triste, catastrófico, estávamos há uma semana da estreia. Eu disse para o Ghigonetto: "tá complicado né?" ele afirmou perguntando o que se poderia fazer, perguntei: "posso mexer um pouco?" e ele respondeu: "claro, fica à vontade". Na verdade, eu não sabia o que eu iria fazer, mas eu fiz, como faço até hoje, as possibilidades de espetáculo. A Hulda 
Machado, fazia uma vendedora de tecidos, coisa muito normal para a época, que entrava muito calmamente. Como eu não sabia o que fazer, pensei: "vou começar por aí", eu tenho que botar vida aí dentro. A primeira coisa que me veio a cabeça foi colocar música brasileira na cena, ou seja, o Brasil começou a entrar dentro do espetáculo, e os atores começaram a se entusiasmar. Eles começaram a entender a peça, começaram a mudar o jogo deles. Fizemos a cena e a cena ficou maravilhosa! O elenco chegou pra mim e disse: "Amir, volta amanhã!", o Carlos Miranda [produtor] também disse: "Amir, não vai embora. Volta amanhã!" No dia seguinte eu voltei, e o Serginho [Mamberti] já chegou me dizendo "Amir vê essa cena pra mim", outras pessoas também, e eu comecei a mexer em cada uma e fui tirando os lençóis da sacola. Fomos indo, indo e indo, todos muito entusiasmados. No terceiro dia, a peça começou a crescer e a crescer... Quando nós olhamos para trás, o Ghigonetto não estava mais na plateia. Iriamos estrear faltando cinco dias. O Carlos Miranda me disse: "vai em frente cara!" o elenco todo também. No dia da estreia ele apareceu e eu não apareci. A peça fez um enorme sucesso, ficou muito tempo legal. Bonito, poético, brasileiro demais. E era uma recuperação de uma dramaturgia brasileira, do tipo de uma representação brasileira, de um ator brasileiro, representado ali pela Iracema de Alencar, era uma homenagem pra ela. (HADDAD. Amir Haddad em conversa para Luiz Campos em 2014)

A citação precisou ser extensa, pela dimensão de seu conteúdo, para que o leitor, assim como eu, perceba que a participação de Amir Haddad para montagem foi fundamental para que esse popular surgisse na encenação proposta, indo de encontro com as afirmações anteriores de Hall e Abreu, onde "as transformações são operadas" e "a cultura popular não se conceitua, enfrenta-se". Abreu (2003) completa seu pensamento sobre cultura popular:

É algo que precisa sempre ser contextualizado e pensado a partir de alguma experiência social e cultural, seja no passado ou no presente; na documentação histórica ou na sala de aula. O conceito só emerge na busca do como as pessoas comuns, as camadas pobres ou os populares (ou pelo menos o que se considerou como tal) enfrentam (ou enfrentaram) as novas modernidades (nem sempre tão novas assim); de como criam (ou recriaram), vivem (ou viveram), denominam (ou denominaram), expressam (ou expressaram), conferem significados (ou conferiram) a seus valores, suas festas, religião e tradições, considerando sempre a relação complexa, dinâmica, criativa, conflituosa e, por isso mesmo, política mantida com os diferentes segmentos da sociedade. (ABREU, 2003, p.13)

Talvez agora possamos ter uma clareza maior das escolhas do Grupo Decisão, e associar que a cultura popular foi uma escolha estratégica de montagem. Provavelmente, quando o diretor Amir Haddad nos revela que a montagem estava "quadrada" ele refere-se a uma proximidade com o seu público, e que talvez não estaria acontecendo, pois uma identificação era necessária e precisava estar presente na montagem. E tudo nos leva a crer que esse objetivo foi alcançado com "O Patinho Torto". O texto foi além da 
recuperação de um dramaturgo que não era muito encenado, mas também de um tema que continha nas suas entrelinhas uma visão moderna e próxima para época. Vimos também um diretor que em meio a limitações artísticas, ou habituado a montagens para um teatro com outros moldes, contrariado ou não, aceitou a colaboração de um diretor convidado, e manteve suas indicações, acrescentando uma popularidade para o espetáculo. O resultado surge em inúmeras críticas, e depoimentos da grande aceitação do público nessa montagem popular.

Não podemos deixar passar despercebido o fato de que a montagem estreou meses após o período em que se instaurou a ditadura no país. Nesse período, como pesquisas existentes já apontaram, existiu uma perseguição aos artistas da época, e muitos grupos tiveram que mudar suas estratégias de montagens.

Nem na ficha técnica dos programas das temporadas nas cidades do Rio de Janeiro e São Paulo, e muito menos em todas os documentos encontrados, o crédito ao Amir Haddad foi atribuído no espetáculo. Não só João das Neves, mas também Sergio Mamberti e Suely Franco em conversas posteriores, afirmaram a contribuição do diretor carioca. Obviamente que Antonio Ghigonetto, também contribuiu para o sucesso da montagem, mas sabemos que as atribuições da encenação não foram feitas sozinhas. E apenas com pesquisas como está, são capazes de trazer à tona informações ocultas da história, que por algum motivo foram ofuscadas. 


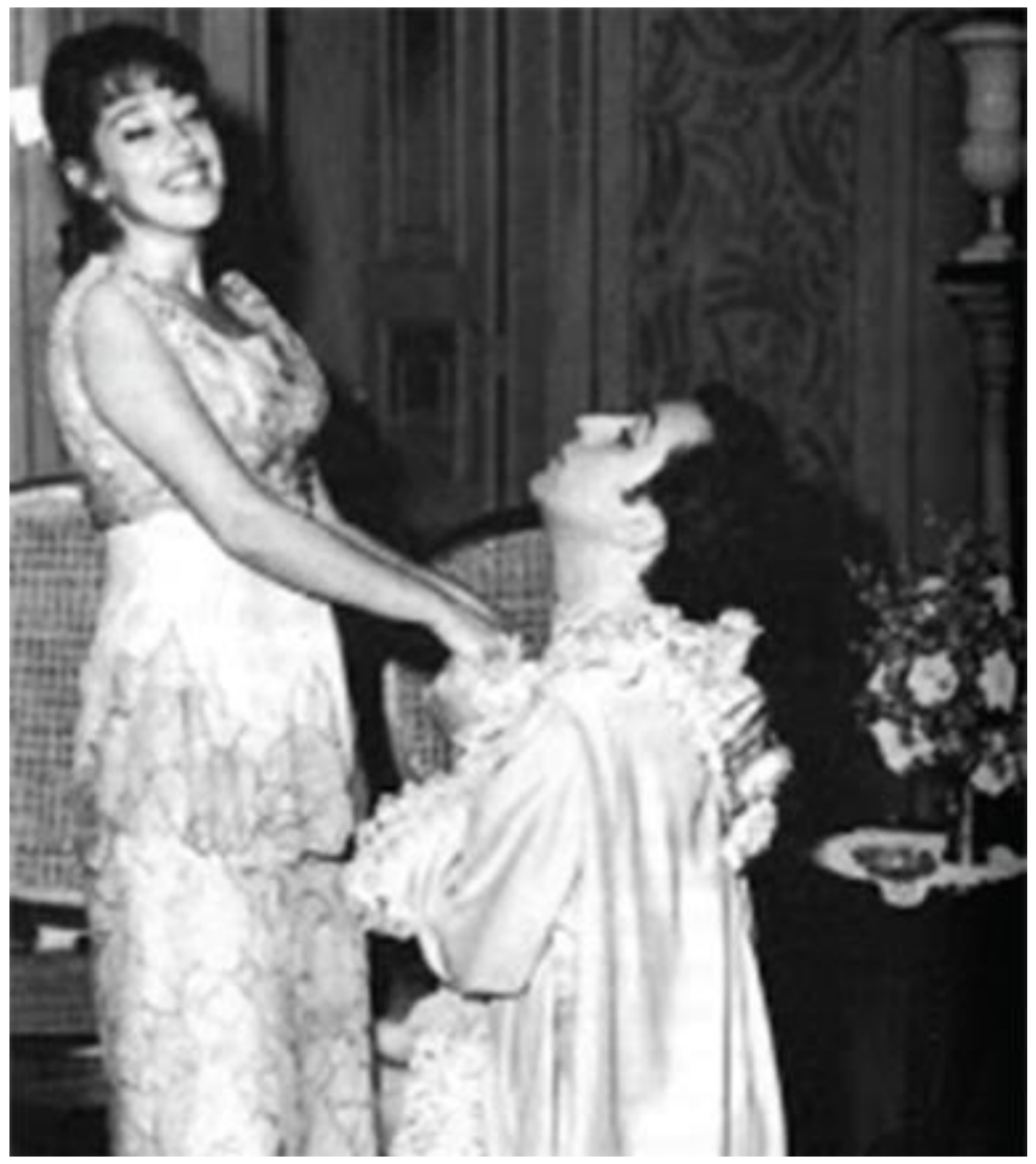

Foto 3. Suely Franco e Emilio Di Biasi. Acervo: Luiz Campos. 


\section{REFERÊNCIAS}

ABREU, Martha. Cultura popular: um conceito e várias histórias. In ABREU, Martha e SOIHET, Rachel (Orgs) Ensino de história: conceitos, temáticas e metodologia. Rio de Janeiro (RJ). Casa da Palavra, 2003.

AZEVEDO, Almir. "O patinho torto ou os mistérios do sexo". A Noite, Rio de Janeiro, 22 Jul. 1964, p.4.

CAMPOS, Luiz. Ghigonetto, um homem de teatro. São Paulo: Giostri, 2017.

HALL, Stuart. Da diaspora: Identidades e mediacoes culturais. Belo Horizonte: Editora UFMG; Brasilia: Representacao da UNESCO no Brasil, 2003.

JAFA, Van. "O patinho torto ou os mistérios do sexo". Correio da Manhã, Rio de Janeiro, 24 jul. 1964, p. 2.

MOURA, A. Heleniara. O itinerário da atriz Lysia de Araújo nos anos 1960: uma década de teatro em São Paulo. Anais da Abrace, 2016. Disponível em file://C:/Users/Luiz\%20Campos/Downloads/1729-5259-1-PB.pdf . Acesso em 05 de out. 2018

NERES, José / MORAES,G. Alice. A Homossexualidade feminina no teatro de Coelho Neto, 2017. Disponível em http://conhecimentoliteratura.com.br/ahomossexualidade-feminina-no-teatro-de-coelho-neto/ Acesso em 30 de ago. 2018.

RIEDEL, Erika (org.). Emilio Di Biasi: o tempo e a vida de um aprendiz. São Paulo: Imprensa Oficial do Estado de São Paulo, 2010.

TIBAJI, F. R. J. Alberto. Apontamentos e reflexões sobre as relações entre o teatro no Brasil e diversidade sexual. Belo Horizonte: Revista o eixo e a roda, 2017.

Recebido em agosto de 2018.

Aprovado em outubro de 2018. Publicado em dezembro de 2018. 